\title{
Fundamento jurídico de la acción judicial de restitución y formalización de tierras y su carácter predominante como medida de reparación*
}

\author{
Lady Tatiana Suárez Varón**
}

Recibido: 12 de octubre de 2018 - Aprobado: 18 de enero de 2019

\section{Resumen}

Este artículo aborda un tema que en la actualidad y desde hace ya varios años se ha venido desarrollando en nuestro país: se trata de la acción judicial de restitución y formalización de tierras, su fundamento jurídico, su finalidad y su naturaleza, así como los órganos y las autoridades encargadas de su trámite. Todo ello con el fin de determinar la efectividad de este mecanismo en relación con sus objetivos, tales como garantizar la prevalencia de los derechos de las víctimas del abandono y despojo forzado de sus tierras, al encontrarse por tal situación como sujetos de vulnerabilidad manifiesta. Se realizó una investigación cualitativa y descriptiva para determinar cómo, a través de esta herramienta, se pretende otorgar el debido respeto y restablecimiento de los derechos de las víctimas del conflicto armado colombiano. Se concluyó que, por su finalidad y naturaleza, esta acción es un mecanismo que aunque paulatino se considera efectivo para lograrlo.

Palabras clave: constitución, conflicto armado, propiedad, titularidad.

* $\quad$ Este artículo es producto del proyecto de investigación "Fundamento jurídico de la acción judicial de restitución y formalización de tierras y su carácter predominante como medida de reparación”, gestionado en la Universität Konstanz, en Alemania. Citar como: Suárez Varón, L. T. (2019). Fundamento jurídico de la acción judicial de restitución y formalización de tierras y su carácter predominante como medida de reparación. Revista IUSTA, 51(2), 91-114. DOI: https://doi. org/10.15332/25005286.5037

** Abogada de la Universidad Católica de Colombia y especialista en Derecho Administrativo, Bogotá, Colombia. Orcid: https://orcid.org/0000-0002-2752-9890. Correo electrónico: tatianasuarezvar@gmail.com 


\title{
LEGAL BASIS OF THE LEGAL ACTION OF RESTITUTION AND FORMALIZATION OF LAND AND ITS PREDOMINANT NATURE AS REPARATION MEASURE
}

\begin{abstract}
This article approaches an issue that has been ongoing in our country for several years now, namely the legal action for the restitution and formalization of land, its legal basis, its purpose and its nature, as well as the bodies and the authorities responsible for processing them. All this in order to determine the effectiveness of this mechanism in relation to its purposes, such as guaranteeing the prevalence of the rights of the victims of forced abandonment and dispossession of their lands, as they are considered evident vulnerable subjects. A qualitative and descriptive research was conducted to determine how, through this tool, it is intended to grant the due respect and restoration of the victims' rights of the Colombian armed conflict, and it was concluded that, due to its purpose and nature, this action is a mechanism that, although gradual, is considered effective to achieve it.
\end{abstract}

Keywords: constitution, armed conflict, property, ownership.

\section{FundaMENTO JURÍDico dA AÇÃo JUdiCIAL DE RESTITUIÇÃo E FORMALIZAÇÃO DE TERRAS E SEU CARÁTER PREDOMINANTE COMO MEDIDA DE REPARAÇÃO}

\section{Resumo}

Este artigo aborda um tema que na atualidade e desde há vários anos tem se desenvolvido em nosso país, trata-se da ação judicial de restituição e formalização de terras, seu fundamento jurídico, sua finalidade e sua natureza, assim como dos órgãos e das autoridades encarregadas de seu trâmite. Tudo isso com o objetivo de determinar a efetividade de este mecanismo em relação com seus objetivos, tais como garantir a prevalência dos direitos das vitimas do abandono e despojo forçado de suas terras, ao se encontrar por essa situação como sujeitos de vulnerabilidade manifesta. Realizou-se uma pesquisa qualitativa e descritiva para determinar como através de esta ferramenta, pretende-se outorgar o devido respeito e restabelecimento dos direitos das vitimas do conflito armado colombiano e conclui-se que, por sua 
finalidade e natureza, esta ação é um mecanismo mesmo que paulatino considera-se efetivo para alcançá-lo.

Palavras-chave: constituição, conflito armado, propriedade, titularidade.

\section{Introducción}

Históricamente, todas las sociedades han atravesado diversas dificultades en torno a la tierra, ${ }^{1}$ con lo cual se han afectado aspectos de carácter social, económico y político. Y, por supuesto, Colombia no es la excepción, y menos durante la vigencia de un conflicto armado interno. Para dar manejo y trámite a estas cuestiones, se hace necesaria la expedición de normas que permitan darle un horizonte al problema presentado alrededor de este tema de gran importancia. Por ello, durante mucho tiempo, en nuestro país se han presentado varias reformas a los derechos sobre la tierra, ${ }^{2}$ a través de las cuales se ha pretendido asignar o reconocer a cada quien el derecho de goce y titularidad de las tierras y más aún si son personas víctimas del referido conflicto.

En este sentido, es menester tener en cuenta que las primeras normas que regulaban el acceso y la distribución de la tierra contenían su fundamento en disposiciones agrarias, ${ }^{3}$ en derecho privado y en derecho civil, por tanto, se pudo evidenciar que

1 Frente a este problema acerca del acceso a la tierra en Colombia, la Sentencia C-330/2016, de 23 de junio hace referencia al desarrollo histórico del acceso a la tierra y su titularidad, teniendo que para 1819 empezó a darse importancia a la estructura agraria del país. Ahora bien, frente a la titularidad de la tierra, en la referida sentencia, también se indica que, para 1926, "el proceso hacia otras formas de acceso a la tierra se suele asociar a una decisión judicial proferida por la Corte Suprema de Justicia, de 1926, en la que se estableció que, quien pretendiera un derecho sobre una porción de tierra rural debía estar en capacidad de demostrar un título original". Para el mismo año, se expidió la Ley 74/1926, de 30 de noviembre que exigió a los propietarios la presentación del material probatorio judicial de sus títulos y le otorgó al Estado, por primera vez, la posibilidad de expropiar las tierras con fines de parcelación.

2 De acuerdo con los diversos problemas presentados en torno a la estructura agraria del país, las evoluciones sociales y la reforma constitucional introducida en 1936, se estableció una característica importante sobre la propiedad, de modo que esta ostentaba una figura conocida como la función social de la propiedad, que incluyó en la Carta Política la necesidad de permitir que la propiedad sirviera, no "solo al interés privado de su dueño o titular, sino también a los intereses sociales, en especial de los campesinos" (Sentencia C-644/2012, de 23 de agosto).

3 La primera reforma agraria se presenta con la expedición de la Ley 200/1936, de 16 de diciembre, con la cual se dio un carácter social en torno al acceso a la propiedad, bajo el lema "La tierra es para quien la trabaja”, que estableció un conjunto de medidas alrededor del acceso a la propiedad 
era necesario hacer frente a la especialidad y a la importancia de la situación y crear una herramienta encaminada a la reparación integral de las víctimas ${ }^{4}$ del conflicto armado y al restablecimiento de sus derechos. Por ello, se precisó la adecuación de las normas existentes que regulaban los temas concernientes a las víctimas y a sus derechos sobre la propiedad, de modo que fue imperioso expedir una ley que permitiera dar precisión al trámite para salvaguardar los derechos de estas y otorgar el debido acompañamiento por parte del Estado colombiano. Así fue que se dio lugar a la promulgación de la Ley 1448/2011, de 10 de junio, que abrió las puertas a un procedimiento especial, con el cual se busca la garantía, el restablecimiento y la protección de los derechos fundamentales, civiles y humanos de las víctimas del conflicto armado. En definitiva, así es que nace la acción de restitución y formalización de tierras, mecanismo objeto de estudio en la presente investigación.

De manera que la pregunta que surge en particular es la de saber: ¿qué carácter jurídico sustenta la acción judicial de restitución y formalización de tierras como mecanismo de reparación para reconocer y restablecer los derechos de las víctimas del conflicto armado en Colombia?

De igual forma, es pertinente mencionar que la acción judicial de restitución y formalización de tierras posee un alcance bastante amplio, pues, como se mencionó, se pretende ofrecer a las víctimas justicia y reparación frente a sus derechos vulnerados. Por ello, el desarrollo de este trabajo se adelantó a través de una

para los colonos que trabajaran la tierra y la amenaza constante de expropiación en caso de ausencia de explotación por parte de los propietarios. Luego de esta ley, se promulgaron otras leyes que buscaban regular el régimen de tierras, pero una de las disposiciones más importantes se dio con la expedición de la Carta Política de 1991, "entre cuyos rasgos centrales se encuentra: la función social de la propiedad, aunada a una función ecológica; la imprescriptibilidad de los bienes baldíos de la nación; los mandatos expresos de fomento al acceso a la tierra de los trabajadores agrarios y fomento a la producción agropecuaria y de alimentos; el conjunto de mandatos que conforman la Constitución Ecológica, y que tienen notable incidencia en el acceso, uso y distribución de la tierra (definiendo nuevos límites geográficos, creando prohibiciones para un desarrollo sostenible y obligando a Estado y particulares a la adopción de medidas positivas de diversa índole), y la protección de tierras de comunidades o pueblos étnicamente diferenciados"(Sentencia C-330/2016, de 23 de junio).

4 Artículo 3 de la Ley 1448/2011, de 10 de junio: "Son víctimas aquellas personas que individual o colectivamente hayan sufrido un daño por hechos ocurridos a partir del $1^{\circ}$ enero de 1985 , como consecuencia de infracciones al Derecho Internacional Humanitario o de violaciones graves y manifiestas a las normas internacionales de Derechos Humanos, ocurridas con ocasión del conflicto armado interno". Ahora, la Sentencia C-253A/2012, de 29 de marzo indica que "tal definición está con un alcance operativo que se orienta a fijar el universo de los destinatarios de las medidas especiales de protección previstas en la ley, en la que también se parte de un reconocimiento de la dignidad de todas las personas que han sufrido las consecuencias del conflicto armado interno". 
investigación cualitativa y descriptiva, para así determinar y especificar el carácter legal de la acción judicial de restitución y formalización de tierras, su naturaleza, su fundamento jurídico y finalidad.

Ahora bien, recurriendo al método de investigación deductivo, lógico-analítico e histórico, se evaluaron las características de la acción judicial de restitución y formalización de tierras, e históricamente se analizó la normativa desarrollada en nuestro país hasta la actualidad, así como la consulta de jurisprudencia nacional, trabajos de algunos autores nacionales y la observación de revistas indexadas, las cuales permitieron determinar el carácter jurídico fundamental de la acción judicial de restitución y formalización de tierras.

Finalmente, se abordarán las conclusiones que permiten dar respuesta a la pregunta de investigación que en este trabajo se presenta, al dar lugar a reconocer el carácter o fundamento jurídico principal o preponderante de la acción judicial de restitución y formalización de tierras en nuestro país, y arrojar como respuesta su carácter mixto y amplio frente a su conformación y objetivo.

\section{Marco jurídico y procedimiento de la acción judicial de restitución y formalización de tierras como medida de reparación}

Fundamento legal y jurisprudencial de la acción judicial de
restitución y formalización de tierras como medida de reparación

En nuestro país, el marco normativo que regula la acción judicial de restitución y formalización de tierras, como mecanismo de reparación integral para las víctimas del conflicto armado en Colombia, es la Ley 1448/2011, de 10 de junio, con la cual, entre otras medidas y disposiciones, se procuró otorgar el reconocimiento y resarcimiento de los derechos de las víctimas y facilitar así su acceso a la justicia, la verdad y la reparación, ${ }^{5}$ para con ello tratar de restablecer su situación anterior

\footnotetext{
Antes de la entrada en vigencia de la Ley 1448/2011, de 10 de junio, en nuestro país ya se habían expedido otras dos leyes trascendentales para el manejo de las políticas sobre las víctimas del conflicto armado interno. "Estas leyes son la 387 de 1997, sobre desplazamiento forzado, y la 975 de 2005, o Ley de Justicia y Paz. Son leyes que han tratado de reparar a las víctimas desde perspectivas diversas, pero que esencialmente se han enfocado en el mismo objetivo: ofrecer justicia y medidas que reparen a las víctimas" (Álvarez, 2016).
} 
al conflicto, en espacios individuales, materiales, simbólicos morales y colectivos, permitiendo con ello el retorno de las víctimas a su lugar de domicilio y la restitución de sus predios. ${ }^{6}$

Ahora bien, el artículo 72 de dicha ley describe que la restitución deberá ser aplicada a una dimensión material y jurídica ${ }^{7}$ sobre los predios despojados, y en caso de no ser viable la restitución de las mismas tierras, se deberá acudir al reconocimiento de determinada compensación pecuniaria. Tal compensación deberá estar a cargo del patrimonio del fondo de la Unidad Administrativa Especial de Gestión de Restitución de Tierras Despojadas, según el artículo 97, como reconocimiento y opción subsidiaria de reparación (Pérez, 2013).

Antes de la promulgación de la Ley 1448/2011, de 10 de junio, el Gobierno nacional buscaba hacer frente a la situación de choque y vulneración de derechos que atravesaba el país con ocasión del conflicto armado: con la expedición de la Ley 975/2005, de 25 de julio, con la cual se pretendió facilitar los procesos de paz con los grupos al margen de la ley, tratando de garantizar los derechos de las víctimas, tales como la justicia, la verdad y la reparación. Frente a este último derecho, es necesario hacer referencia al artículo 8 que puntualiza:

Derecho a la reparación. El derecho de las víctimas a la reparación comprende las acciones que propendan por la restitución, indemnización, rehabilitación, satisfacción; y las garantías de no repetición de las conductas.

Restitución [las cursivas son mías] es la realización de las acciones que propendan por regresar a la víctima a la situación anterior a la comisión del delito.

Con la expedición de la Ley 975/2005, de 25 de julio, el Gobierno Nacional pretendía dar cabida a la restitución de tierras que habían sido despojadas como consecuencia del conflicto armado; sin embargo, los resultados de esta ley no fueron los esperados, pues tuvo escasos efectos. Por ejemplo, es propicio referirnos

6 En caso de no ser posible regresarlos a su lugar de residencia, antes de poseer la calidad de víctima, deberán ser reubicados voluntariamente en condiciones de seguridad, sostenibilidad y dignidad (Sentencia C-099/2013, de 27 de febrero).

7 El principal derecho que posee una víctima del conflicto armado y que con ocasión de ello fue despojado y desplazado de sus tierras es la restitución física y jurídica del bien inmueble, en su calidad de ocupante, poseedor o propietario, situación última en la que deberá contar con el título de dominio inscrito (Martínez y Pérez, 2012). 
a la composición del Fondo para la Reparación a las Víctimas, que se creó con el artículo $54,{ }^{8}$ pues este se encontraba integrado, por una parte, con bienes devueltos o entregados por las personas desmovilizadas de los grupos organizados al margen de la ley, que en su gran mayoría estaban deteriorados, inservibles, o se encontraban con medidas cautelares vigentes que daban lugar a cualquier propósito menos a una reparación ${ }^{9}$ a las víctimas.

Ahora bien, según lo anterior, se hizo imperiosa la expedición de una nueva ley que fortaleciera ese propósito, por ello la Ley 1448/2011, de 10 de junio crea un procedimiento de carácter especial, distinto de los procedimientos tradicionales y rígidos, para que estos colombianos en su desafortunada calidad de víctimas de desplazamiento forzoso tengan las herramientas necesarias para acceder a la posibilidad de lograr la restitución ${ }^{10}$ física y jurídica de los predios despojados según corresponda (Observatorio de Restitución y Regulación de Derechos de Propiedad Agraria, 2013).

En suma, se puede comprobar cómo con la normativa expedida a lo largo de estos años y la que nos rige actualmente se está en la búsqueda de la protección de un derecho civil muy importante y regulado desde hace ya muchos años, que es el derecho a la propiedad, y junto con el proceso de restitución de tierras, se busca, además, la reparación de las víctimas del conflicto a través de la formalización ${ }^{11}$ de los derechos de propiedad sobre la tierra, en virtud de que,

8 A este fondo se le dio continuidad en la Ley 1448/2011, de 10 de junio y se buscó su fortalecimiento y sostenibilidad a través de un plan nacional de financiación por medio del documento Conpes 3715/2012, de 30 de mayo. Este fondo es el instrumento financiero principal para la restitución de tierras y pago de compensaciones reguladas por la Ley 1448/2011, de 10 de junio, y se encuentra adscrito a la Unidad Administrativa Especial de Gestión de Restitución de Tierras Despojadas (UAEGRTD).

9 Entendida la reparación "no solo como una forma de justicia correctiva, que busca enfrentar el sufrimiento ocasionado a las víctimas y a sus familiares por hechos atroces, sino también como una oportunidad de impulsar una transformación democrática de las sociedades" (Díaz, Sánchez y Uprimny, 2009).

10 "La restitución es un concepto jurídico que se aplica a distintas situaciones. Existe la restitución ordinaria del Código Civil y el Código de Procedimiento Civil, la restitución por vía administrativa, y la restitución especial contenida en la Ley 1448 de 2011. La última entiende por restitución la realización de medidas para el restablecimiento de la situación anterior a las violaciones de la norma" (Observatorio de Restitución y Regulación de Derechos de Propiedad Agraria, 2013).

11 Esa formalización se realiza a través de sentencias, dentro de las cuales se emiten órdenes judiciales dirigidas a ciertas entidades del orden territorial para que se reconozcan y formalicen "los derechos de propiedad sobre la tierra para las personas restituidas: que comprende la expedición de títulos de adjudicación, actualización de datos cartográficos, números de matrícula e inscripción predial" (Moreno, Medina, Fuentes y Lopera, 2016). 
la principal relación jurídica que ejercen las personas con la tierra es la propiedad; esta constituye el primer derecho real, pues los demás derechos de este tipo son sus desmembraciones o variaciones, como ocurre con el usufructo, el uso o habitación, la servidumbre, la prenda, y la hipoteca. Junto con la propiedad, se generan otro tipo de relaciones con la tierra como la posesión, la ocupación y la tenencia, que también son objeto de reconocimiento legal. (Fuentes, 2011)

Igualmente, se hace necesario siquiera referir grosso modo los instrumentos internacionales con los que cuenta nuestro país para reforzar la búsqueda de la reparación de las víctimas dentro de un escenario de justicia transicional ${ }^{12}$ para así proteger el derecho a la propiedad tanto individual como colectiva, con una serie de tratados ratificados por el Estado colombiano que se incorporan al ordenamiento jurídico interno, y forman parte del tan importante bloque de constitucionalidad, ${ }^{13}$ noción desarrollada en sentencias como la Sentencia C-225/1995, de 18 de mayo y la Sentencia C-774/2001, de 25 de julio, entre otras.

Para el caso que nos ocupa, uno de los instrumentos más destacados que sirven de apoyo a este derecho es la Declaración Universal de Derechos Humanos, que en su artículo 17 menciona que "toda persona tiene derecho a la propiedad, individual y colectivamente” y que ninguna persona podrá ser privada de forma arbitraria de su propiedad, así como lo dispone la Declaración Americana de los Derechos y Deberes del Hombre en su artículo Xxiı que estipula que toda persona tiene derecho "a la propiedad privada correspondiente a las necesidades esenciales de una vida decorosa, que contribuya a mantener la dignidad de la persona y del hogar", entre otros (Sänger, 2015).

12 El concepto de justicia transicional entendido como el "sistema excepcional de aplicación de justicia por medio del cual se buscan resolver conflictos civiles con base en principios constitucionales y figuras extraordinarias, dejando a un lado la rigidez y rigurosidad de las normas procesales que regulan los procedimientos civiles, de modo que considere y favorezca a la parte débil del proceso", y así pasar de una sociedad colombiana en un "contexto de violencia a uno de paz con una democracia vigorosa e incluyente” (Ministerio de Agricultura y Desarrollo Rural [MinAgricultura], 2012).

13 'El 'Bloque de Constitucionalidad' es una figura desarrollada por la jurisprudencia de la Corte Constitucional a partir de 1995 para explicar la existencia de normas y principios que, sin estar expresamente contenidos en el texto constitucional, se consideran incorporados a él" (Fuentes, 2011). 


\section{Procedimiento de la acción judicial de restitución y formalización de tierras}

El procedimiento creado para la consecución de la acción de restitución de tierras se caracteriza por su especialidad, ya que consiste en dos etapas: una de carácter administrativo y una de carácter judicial. Inicia con la etapa administrativa, no de forma arbitraria, sino porque es la etapa por la que debe iniciar la víctima su reclamación llamada acción judicial de restitución y formalización de tierras, ${ }^{14}$ la cual fue creada bajo el entendido de facilitar a las víctimas el acceso a la justicia y la reparación dentro del contexto de la justicia transicional. Por ello, su procedimiento es de carácter exclusivo, de modo que no se puede concebir como un mecanismo tradicional o rígido que necesariamente deba estar acompañado de formalismos superfluos o periodos extensos como en la justicia ordinaria, teniendo como prevalencia el derecho sustancial sobre las formalidades; procedimiento contemplado en el artículo 76 de la Ley 1448/2011, de 10 de junio.

Para empezar, la etapa administrativa inicia con la recepción de la solicitud de inscripción ${ }^{15}$ al Registro de Tierras Despojadas y Abandonadas Forzosamente. Tal solicitud deberá contener información sobre la relación jurídica de la víctima con la tierra o predios despojados, el relato de los hechos, así como la identificación y localización del predio. Luego de recibida la solicitud, se abrirá espacio al estudio y análisis previo de la petición, dentro del cual se evaluará si cumple o no con los

14 Esta acción fue producto de los requerimientos hechos por la Corte Constitucional, a través de los actos de seguimiento relacionados con la Sentencia T-025/2004, de 22 de enero, mediante los cuales ordenó al Estado colombiano redefinir las políticas sobre tierras en pro de la población desplazada, víctima de la violencia. Así es como a través del Auto 008/2009, de 26 de enero se exhorta al Estado colombiano a "diseñar y poner en marcha un mecanismo especial para recibir, tramitar y resolver las reclamaciones de restitución de tierras de las víctimas de abandonos o despojos, teniendo en cuenta las distintas formas de relación jurídica de la población desplazada con los predios abandonados (propiedad, posesión, tenencia, etc.)”. En la sentencia mencionada, también se declaró la presencia de un estado de cosas inconstitucional en la población desplazada como retroceso en la protección de sus derechos.

15 Según la Ley 1448/2011, de 10 de junio y el Decreto 4829/2011, de 20 de diciembre, tal inscripción podrá realizarla la UAEGRTD de oficio, un juez voluntariamente según el artículo 4, numeral 4 de la Ley 1437/2011, de 8 de enero o a solicitud de parte. Esta última puede ser la persona interesada o víctima de desplazamiento o despojo, la cual podrá actuar dentro del proceso como titular del derecho, es decir, como propietario, como poseedor o como ocupante, pero a su vez dicha solicitud también puede ser presentada por los cónyuges o compañeros permanentes de las víctimas en el momento de los hechos, por los menores de edad o sucesores a través de la UAEGRTD. Asimismo, la solicitud podrá ser presentada a través de un abogado que cuente con el respectivo poder. 
requisitos ${ }^{16}$ para que el predio referido sea incluido dentro del respectivo registro. Cabe resaltar que en esta etapa se respetará y garantizará el derecho a la defensa y la contradicción, de modo que quien se halle interesado o habitando el predio objeto de registro pueda enterarse de tal solicitud, para que en el curso del procedimiento se haga parte del proceso, a fin de acreditar la legalidad en la adquisición del predio identificado en la solicitud o para que acredite que se encuentra dentro de los supuestos de tercero de buena fe exento de culpa (Ministerio de Agricultura y Desarrollo Rural [MinAgricultura], 2012).

Ahora bien, tal solicitud se presentará ante la Unidad Especial de Gestión de Restitución de Tierras Despojadas (UAEgrTD), que será la encargada de la conformación y administración del registro, por tanto, deberá informar sobre el trámite al propietario, poseedor u ocupante ${ }^{17}$ que se encuentre en el predio y contará con el término de veinte días para adelantar las diligencias previas, obtener el compendio probatorio y así analizar la solicitud. Acabado este tiempo, la UAEGRTD contará con sesenta días ${ }^{18}$ para decidir si es procedente o no la inclusión ${ }^{19}$ del predio en el Registro de Tierras Despojadas y Abandonadas Forzosamente. Decisión que será de suma importancia, ya que es requisito de procedibilidad para acudir a los jueces de restitución, toda vez que en caso de que se decida inscribir o incluir el bien en dicho registro se emitirá la respectiva certificación, sin la cual la demanda o solicitud de restitución será rechazada de plano por los jueces o magistrados encargados.

En vista de lo referido, el paso siguiente y final de esta etapa, luego de que la UAEGRTD incluya la solicitud en el Registro de Tierras Despojadas y Abandonadas

16 Los cuales corresponden a los artículos 3, 75 y 81 de la Ley 1448/2011, de 10 de junio, que en suma son: a) tener la calidad de víctima del conflicto armado interno, b) haber sido despojado de sus tierras con ocasión de tal conflicto y c) ostentar la calidad de propietario, poseedor u ocupante.

17 De acuerdo con el inciso 3 del artículo 76, la UAEGRTD deberá proceder de la siguiente manera: "Cuando resulten varios despojados de un mismo predio o múltiples abandonos, la Unidad los inscribirá individualmente en el registro. En este caso se tramitarán todas las solicitudes de restitución y compensación en el mismo proceso”. De tal manera que la UAEGRTD en pro de garantizar el derecho al debido proceso de los terceros intervinientes les da el reconocimiento e inclusión para convertirse en opositores en sede judicial.

18 Estos serán prorrogables por treinta días más a través de decisión motivada, cuando existan circunstancias que sobrevengan y justifiquen la ampliación del término.

19 La inclusión o no del predio se realizará a través de acto administrativo motivado, contra el cual procederán los recursos legales correspondientes, situación descrita en la Sentencia C-715/2012, de 13 de septiembre en la que se refiere que, "ante la negativa de la Unidad Administrativa de incluir en el registro a determinado predio, la víctima cuenta con mecanismos de defensa para controvertir o impugnar dicha decisión y poder acceder al procedimiento establecido por la Ley para la restitución de sus derechos". 
Forzosamente, será presentar la demanda ${ }^{20}$ ante los jueces o magistrados civiles especializados, que, según el artículo 79 de la Ley 1448/2011, de 10 de junio, están facultados para conocer la acción de restitución y formalización de tierras procedente para los casos de víctimas del conflicto armado interno en nuestro país.

Dando continuidad al procedimiento de la acción referida, se procederá a mencionar lo correspondiente a la etapa judicial, la cual tendrá su inicio en el momento de ser presentada la demanda ante los jueces civiles del circuito ${ }^{21} \mathrm{o}$ ante los magistrados de los tribunales superiores del Distrito Judicial Sala Civil ${ }^{22}$ según corresponda, todos ellos especializados en restitución de tierras, de modo que son ellos los únicos que conocerán y resolverán de forma prevalente, especial y privada las acciones de restitución y formalización de tierras. En los lugares donde no se cuente con jueces civiles del circuito especializados en restitución de tierras, la demanda podrá ser presentada ante "cualquier juez civil municipal, del circuito o promiscuo, quien dentro de los dos días siguientes deberá remitirla al funcionario competente" (Ley 1448/2011, de 10 de junio, art. 79, par. 2).

Luego de ser presentada la demanda ante el funcionario judicial correspondiente, este verificará los requisitos y procederá a pronunciarse a través de auto sobre la admisión de la solicitud. ${ }^{23}$ Es de aclarar que el juez o magistrado en dicho auto o

20 La demanda podrá ser presentada ante los funcionarios judiciales correspondientes por sí misma o a través de apoderado judicial. Aunque el artículo 82 de la Ley 1448/2011, de 10 de junio refiere que podrá la UAEGRTD representar judicialmente a la víctima, solo si esta última así lo decidiere.

21 Según el artículo 79 de la Ley 1448/2011, de 10 de junio, "los Jueces Civiles del Circuito, especializados en restitución de tierras, conocerán y decidirán en única instancia los procesos de restitución de tierras, los procesos de formalización de títulos de despojados y de quienes abandonaron en forma forzosa sus predios, en aquellos casos en que no se reconozcan opositores dentro del proceso. En los procesos en que se reconozca personería a opositores, los Jueces Civiles del Circuito, especializados en restitución de tierras, tramitarán el proceso hasta antes del fallo y lo remitirán para lo de su competencia al Tribunal Superior de Distrito Judicial”. Este es un proceso de única instancia y solo procederá el recurso de revisión en caso de ser negada la restitución, según el artículo 92 de la referida ley.

22 Según el referido artículo 79 de la Ley 1448/2011, de 10 de junio, los magistrados "decidirán en única instancia los procesos de restitución de tierras y los procesos de formalización de títulos de despojados y de quienes abandonaron en forma forzosa sus predios, en aquellos casos en que se reconozcan opositores dentro del proceso. Así mismo, conocerán de las consultas de las sentencias dictadas por los Jueces Civiles del Circuito, especializados en restitución de tierras".

23 De acuerdo con el artículo 86 de la Ley 1448/2011, de 10 de junio, dentro se este ordenará los siguiente: a) La inscripción de la solicitud en la Oficina de Instrumentos Públicos. b) La sustracción provisional del comercio del predio sobre el cual se adelanta la acción de restitución.c) La suspensión de procesos declarativos de derechos reales que se estén adelantando sobre el referido predio, así como los procesos de restitución de tenencia, sucesorios, de embargo, divisorios, de deslinde y 
a través de cualquier estado "podrá decretar las medidas cautelares que considere pertinentes para prevenir un daño inminente o para hacer cesar el que se estuviere causando sobre el inmueble" (Ley 1448/2011, de 10 de junio, art. 86). Aunado a lo anterior, el juez o magistrado deberá proteger también el derecho al debido proceso de los opositores de la solicitud y de los terceros intervinientes que se consideren con interés dentro del proceso, así como sobre el bien objeto de la acción de restitución. Por lo anterior, las personas que se consideren como tales deberán presentarse ante el juez o magistrado dentro de los quince días siguientes a la solicitud, de modo que "las oposiciones a la solicitud efectuadas por particulares se presentarán bajo la gravedad del juramento y se admitirán, si son pertinentes”. ${ }^{24}$ Acto seguido, se abrirá un periodo de pruebas por un espacio de treinta días a través de los cuales el juez o magistrado, cuando llegue a su pleno convencimiento, podrá proferir sentencia ${ }^{25}$ sin necesidad de decretar o practicar más pruebas solicitadas dentro del proceso; fallo que deberá contener la decisión definitiva sobre la propiedad, posesión u ocupación del bien objeto del litigio, así como decretará las compensaciones a las que haya lugar a los opositores de buena fe exentos de culpa que se hubieren hecho

amojonamiento, declaración de pertenencia y de bienes mostrencos y vacantes, servidumbres, posesorios; así como los procesos ejecutivos, judiciales, administrativos y notariales que se hubieren iniciado ante la justicia ordinaria o entidades competentes sobre el bien objeto de la acción de restitución de tierras antes de la presentación de la misma. d) La notificación del inicio del proceso al representante legal del municipio donde se encuentre ubicado el predio y al Ministerio Público. e) La publicación de la admisión de la solicitud en un diario de amplia circulación a nivel nacional, para que quienes se encuentren afectados con tal admisión comparezcan al proceso y hagan valer sus derechos a través de las pruebas necesarias.

24 La UAEGRTD podrá presentar oposiciones cuando no haya actuado como representante de las víctimas y no haya presentado la solicitud. Por tanto, las oposiciones que sean presentadas por ella deberán ser valoradas y tenidas en cuenta por el juez o magistrado que conozca de la acción de restitución.

25 Artículo 91. "Parágrafo 1. Una vez ejecutoriada la sentencia, su cumplimiento se hará de inmediato. En todo caso, el Juez o Magistrado mantendrá la competencia para garantizar el goce efectivo de los derechos del reivindicado en el proceso, prosiguiéndose dentro del mismo expediente las medidas de ejecución de la sentencia, aplicándose, en lo procedente, el artículo 335 del Código de Procedimiento Civil. Dicha competencia se mantendrá hasta tanto estén completamente eliminadas las causas de la amenaza sobre los derechos del reivindicado en el proceso. Parágrafo 2. E1 Juez o Magistrado dictará el fallo dentro de los cuatro meses siguientes a la solicitud. El incumplimiento de los términos aplicables en el proceso constituirá falta gravísima. Parágrafo 3. Incurrirá en falta gravísima el funcionario que omita o retarde injustificadamente el cumplimiento de las órdenes contenidas en el fallo o no brinde al Juez o al Magistrado el apoyo requerido por este para la ejecución de la sentencia. Parágrafo 4. El título del bien deberá entregarse a nombre de los dos cónyuges o compañeros permanentes, que al momento del desplazamiento, abandono o despojo, cohabitaban, así al momento de la entrega del título no están unidos por ley”. Para ampliar las disposiciones del fallo, revisar el artículo 91 de la Ley 1448/2011, de 10 de junio. 
parte del proceso, tras lo cual se constituirá con la sentencia el título de propiedad suficiente para la acreditación del derecho a la propiedad de la víctima solicitante protegido de forma especial por el Gobierno Nacional.

De este primer segmento, se puede advertir que el procedimiento ${ }^{26}$ de la acción de restitución de tierras tiene una naturaleza especial y mixta; en este sentido, se podría indicar que este mecanismo o acción de restitución cuenta con apoyo normativo e institucional para la efectividad y garantía del derecho a la propiedad, que es uno de los derechos de las personas y en especial de las víctimas que deben ser altamente protegidos, promovidos y garantizados por el Gobierno Nacional (Barragán, 2016).

\title{
Alcance constitucional de la acción judicial de restitución y formalización de tierras y sus características especiales para la protección a las víctimas del conflicto armado
}

\author{
Desarrollo constitucional de la acción de restitución \\ y formalización de tierras
}

E1 Estado colombiano dentro de su texto constitucional identifica y define la consolidación de instituciones y autoridades que encuentran su naturaleza en la obtención de los fines del Estado, dentro de los cuales se encuentra garantizar la seguridad nacional de sus habitantes, procurar la dignificación de las personas, vigilar las situaciones jurídicas y sociales entre sus administrados para proteger su vida, creencias, bienes y honra, así como asegurar el cumplimiento de los deberes de carácter social en cabeza de los particulares y a cargo del Estado, todo ello según lo descrito en el artículo 2 de nuestra Carta Política. Por esta razón, en cabeza del Estado se encuentra el deber de evitar el despojo y desplazamiento forzado de los colombianos y, en caso de que esto no se pueda impedir, deberá adoptar las medidas necesarias que resulten efectivas para la protección de los derechos de las víctimas de estos delitos.

26 Para evidenciar las estadísticas de las solicitudes, sentencias y restituciones efectivas hasta mayo de 2018, véase Unidad de Restitución de Tierras (2018). 
Ahora bien, nuestra Carta Política en su artículo 64 también hace referencia a la promoción del "acceso progresivo a la propiedad de la tierra de los trabajadores agrarios, en forma individual o asociativa" para mejoramiento de la calidad de vida de los campesinos. Por tanto, su enfoque va dirigido a los trabajadores agrarios, ${ }^{27}$ mas no a las víctimas del conflicto armado. Así, el alcance constitucional al que se hará referencia en este segmento será de orden jurisprudencial.

Referenciando lo anterior, es menester señalar que el carácter constitucional que ostenta la acción de restitución y formalización de tierras, como mecanismo de reparación a las víctimas de desplazamiento y despojo, con ocasión del conflicto armado interno, está orientado a la garantía del derecho a la reparación de las víctimas, como derecho fundamental, materializando dicha garantía con la protección al derecho a la propiedad de las víctimas. Cabe resaltar que los derechos a la propiedad o posesión de las tierras de las personas no están catalogados como fundamentales, sino que se tendrán como tal solo con ocasión de su conexidad con derechos de carácter fundamental, como el derecho a la vida, el derecho al trabajo, etc., de modo que la Corte Constitucional en la Sentencia T-580/2011, de 27 de julio manifiesta que,

para que proceda la protección inmediata y efectiva del derecho a la propiedad por vía de tutela, debe su desconocimiento afectar derechos que por naturaleza son fundamentales, como la vida, la integridad física, el trabajo, etc. En este contexto, solo la conexidad entre el derecho a la propiedad privada y alguno de los derechos fundamentales esenciales en el desarrollo y ejercicio de las condiciones básicas de

27 Aunque no sea el tema principal, cabe resaltar que el derecho a la propiedad de los campesinos o trabajadores agrarios también podría considerarse como un derecho fundamental en los siguientes términos: "Siguiendo la jurisprudencia constitucional, existen cuatro elementos desde el punto de vista del derecho a la tierra y al territorio, que permiten reconocerlo como fundamental:

- El derecho de los trabajadores agrarios a no ser despojados de su propiedad rural o impulsados a deshacerse de ella so pretexto de su improductividad, sin antes proporcionar alternativas productivas a través de alianzas o asociaciones, o a cambio de otras alternativas como las zonas de reserva campesina.

- El derecho a que el disfrute de la propiedad no sea afectado sin justificación suficiente.

- $\quad$ El derecho a que el Estado adopte medidas progresivas y no regresivas dirigidas a alcanzar el acceso a la propiedad de los trabajadores agrarios y el mejoramiento de su calidad de vida y dignidad humana.

- El derecho a que se proteja la seguridad alimentaria en la población campesina" (Moreno et al., 2016, pp. 255-256). 
vida, permiten al juez de tutela, resolver un asunto de esta índole. La Corte ha entendido que la propiedad, por ser un derecho de naturaleza económica y social, su connotación de "fundamental" dependerá del estudio que el juez constitucional realice en el caso concreto. ${ }^{28}$

Por lo anterior, es importante resaltar que las víctimas de los delitos de despojo y desplazamiento a causa del conflicto interno se encuentran en situación de vulnerabilidad manifiesta, por tanto, el Estado debe contar con las disposiciones y medidas necesarias para superar esa vulnerabilidad y reparar en todas las dimensiones posibles sus derechos como víctimas, así, su situación no puede ser comparada con la protección del derecho a la propiedad de personas que no estén catalogadas o reconocidas como víctimas del conflicto armado. Por ello, en reiteradas oportunidades y en especial en la Sentencia T-821/2007, de 5 de octubre ${ }^{29}$ la Corte Constitucional ha destacado que,

ciertamente, si el derecho a la reparación integral del daño causado a víctimas de violaciones masivas y sistemáticas de derechos humanos, es un derecho fundamental, no puede menos que afirmarse que el derecho a la restitución de los bienes de los cuales las personas en situación de desplazamiento han sido despojadas, es también un derecho fundamental.

${ }_{28}$ De lo anterior se debe aclarar que el procedimiento para alegar y buscar la protección al derecho a la propiedad se debe adelantar a través de otros medios jurisdiccionales por medio de procesos ordinarios o especiales. Conviene subrayar que la acción de tutela no es procedente, porque el derecho a la propiedad no es un derecho fundamental propiamente dicho, como se pudo evidenciar en la Sentencia T-580/2011, de 27 de julio, pero con la expedición de la Ley 1448/2011, de 10 de junio y diversos pronunciamientos sí se le dio ese carácter fundamental a este derecho, únicamente si son víctimas del conflicto armado quienes adelanten esa acción de restitución. Ahora bien, no significa que se pueda adelantar la restitución a través de una acción de tutela, pues, como ya se mencionó, la acción por la cual se busca garantizar ese derecho es la acción objeto de esta investigación y para ello se cuenta con instituciones y jueces especializados en restitución de tierras.

29 Dicha sentencia también menciona que "como bien se sabe, el derecho a la restitución es uno de los derechos que surgen del derecho a la reparación integral. En este sentido es necesario recordar que el artículo 17 del Protocolo Adicional de los Convenios de Ginebra de 1949 y los Principios Rectores de los Desplazamientos Internos, consagrados en el Informe del Representante Especial del Secretario General de Naciones Unidas para el Tema de los Desplazamientos Internos de Personas (los llamados principios Deng), y entre ellos, los Principios 21, 28 y 29 y los Principios sobre la restitución de las viviendas y el patrimonio de los refugiados y las Personas desplazadas, hacen parte del Bloque de constitucionalidad en sentido lato, en tanto son desarrollos adoptados por la doctrina internacional, del derecho fundamental a la reparación integral por el daño causado (C. P, art. 93.2)". Aquí también se menciona la acción de tutela como medio idóneo para el reconocimiento y la protección de los derechos sobre la propiedad o posesión de las víctimas de despojos y desplazamientos. 
Así, luego de varios pronunciamientos de la Corte Constitucional, ${ }^{30}$ y con la expedición de la Ley 1448/2011, de 10 de junio, es claro que el derecho a la propiedad de las víctimas pasó de ser un derecho civil, social y económico a ser un derecho que para las víctimas se considera fundamental per se, ya que se está frente a una relación directa entre el derecho a la propiedad sobre la tierra con la reparación integral a las víctimas. Por eso, la Ley 1448/2011, de 10 de junio en su artículo 72, inciso 4, dispone:

La restitución jurídica del inmueble despojado se realizará con el restablecimiento de los derechos de propiedad o posesión, según el caso. El restablecimiento del derecho de propiedad exigirá el registro de la medida en el folio de matrícula inmobiliaria. En el caso del derecho de posesión, su restablecimiento podrá acompañarse con la declaración de pertenencia, en los términos señalados en la ley.

Con lo anterior, se denota que la protección y reparación a los derechos de las víctimas a la que se está apelando es a la garantía del "derecho fundamental a que el Estado conserve su derecho a la propiedad o posesión y les restablezca el uso, goce y libre disposición del mismo" (Guzmán y Barón, 2018), con lo cual se genera un soporte de orden constitucional a las víctimas para buscar a toda costa la reparación de sus derechos y tratar de volverlos a su situación anterior o mejor, ${ }^{31}$ con el fin del restablecimiento de sus derechos, que, en primer plano, sería el derecho a la propiedad y restitución material y jurídica de sus predios despojados.

\section{Características especiales de la acción judicial de restitución y formalización de tierras}

Con respecto a las características especiales de la acción judicial de restitución y formalización de tierras, aunque ya se abordó en gran parte, es muy importante empezar por mencionar que la solicitud inicial puede ser presentada de forma escrita o verbal por parte de la víctima ante la UAEGRTD (Daza, 2013).

30 Lo afirman también la Sentencia T-085/2009, de 16 de febrero; la Sentencia T-159/2011, de 10 de marzo; la Sentencia C-820/2012, de 18 de octubre; y la Sentencia T-679/2015, de 3 de noviembre.

31 El concepto de reparación transformadora consiste en volverlos a una situación mejor a la que se encontraban antes de la vulneración a sus derechos, de modo que, "de conformidad con lo anterior, el enfoque transformador de las reparaciones consiste no solo en enfrentar el daño que fue ocasionado por los procesos de victimización, sino también las condiciones de exclusión en que vivían las víctimas y que permitieron o facilitaron su victimización” (Moya y Marulanda, 2012,p. 8). 
La naturaleza de esta acción es mixta, como se mencionó en apartes preliminares. Es una acción que sustenta un carácter especial, en la medida en que consta de una etapa administrativa y una judicial. En la primera etapa, que es la administrativa, el organismo encargado de recibir la solicitud de las víctimas es la UAEGRTD, así como será la encargada de adelantar las investigaciones correspondientes y recopilar las pruebas a las que haya lugar, para luego si es procedente inscribir la solicitud e incluir el predio en el Registro de Tierras Despojadas y Abandonadas Forzosamente, para dar continuidad al procedimiento y pasar a la etapa judicial. Estando ya en la etapa judicial, el juez competente sustenta también un carácter especial, puesto que debe ser un juez civil especialista en restitución de tierras y será él quien decida si hay lugar o no a reconocer los derechos de las víctimas en cuanto a la restitución y formalización del predio solicitado o la compensación, ${ }^{32}$ si hay lugar a ello, según el acervo probatorio ${ }^{33}$ aportado al proceso (Gamboa, 2016).

De lo anterior se puede identificar otra especialidad importante del procedimiento, en virtud de que permite invertir la carga de la prueba (Ley 1448/2011, de 10 de junio, art. 78), toda vez que será la UAEgrto la que se encargue de la recolección de estas en favor de la víctima, innovaciones procesales integradas a la Ley 1448/2011, de 10 de junio. Cabe mencionar, entonces, que, la prueba sumaria, las presunciones de despojo o abandono forzado y la presunción de pruebas fidedignas, la posibilidad de que las víctimas acudan directamente y sin necesidad de representante ante los jueces especializados, y la gratuidad del proceso, entre otras medidas, se constituyen en importantes herramientas que imprimen una mayor celeridad y permiten equiparar las cargas de las partes en favor de las víctimas (Guzmán y Barón, 2018, p. 152).

Frente a la denominación de prueba fidedigna, es de resaltar que se refiere a que las pruebas no tendrán que ser verificadas por el juez, ya que solo por el hecho de ser presentadas por la UAEGRTD tendrán pleno valor probatorio, según lo descrito en los artículos 77 y subsiguientes de la Ley 1448/2011, de 10 de junio. Por otro lado, la acción de restitución se adelanta por medio de un procedimiento de única instancia, ya que la Corte Constitucional mediante Sentencia C-099/2013, de 27 de febrero consideró

32 Es importante resaltar que la compensación será reconocida si es imposible restituir el bien solicitado a la víctima o si no hay lugar a la reubicación voluntaria. Ahora bien, la compensación también podrá ser reconocida si así se logra probar a los terceros y opositores de buena fe y exentos de culpa.

33 Pruebas recopiladas por la UAEGRTD independiente de si la víctima decide o no que sean ellos quienes lo representen judicialmente en la segunda etapa del procedimiento, es decir, la etapa judicial. 
razonable esta previsión normativa al ponderar la limitación que entraña la ausencia de una instancia de revisión, con la finalidad constitucionalmente válida perseguida por la norma. Adicionalmente, explicó que el derecho de contradicción, en particular, y el debido proceso en general se encuentran garantizados por la estructura misma del procedimiento de restitución.

A diferencia de lo que se presenta en las demás jurisdicciones, en las que el proceso concluye con la ejecutoria de la decisión de la última instancia, en el proceso de la acción de restitución de tierras, según el artículo 91 de la Ley 1448/2011, de 10 de junio, en su parágrafo 1, prevé que "el Juez o Magistrado mantendrá la competencia para garantizar el goce efectivo de los derechos del reivindicado en el proceso, prosiguiéndose dentro del mismo expediente las medidas de ejecución de la sentencia”, lo cual quiere decir que el proceso finaliza en el momento en que efectivamente se han cumplido las disposiciones de protección y restitución contenidas en el fallo. ${ }^{34}$

Con respecto a los principios ${ }^{35}$ que rigen la acción de restitución de tierras, entre otros, cabe mencionar, por ejemplo, el principio de la buena fe, el cual permite librar a las víctimas de la carga de la prueba y "se dará especial peso a la declaración de la víctima, y se presumirá que lo que esta aduce es verdad, de forma que en caso de duda será el Estado quien tendrá la obligación de demostrar lo contrario" (Sentencia C-253A/2012, de 29 de marzo); el principio de gradualidad y progresividad de la acción, ya que, desde su entrada en vigencia a la fecha, lo que se ha tratado de hacer, por parte de los organismos encargados, es la focalización de los predios, de modo que poco a poco se puedan registrar los predios despojados y abandonados forzosamente, a través de trabajos de macrofocalización y microfocalización de las zonas, que históricamente han sido focos de despojo y abandono, y así garantizar la restitución y dar paso a otro principio: el de la igualdad.

Esta acción debe estar encaminada a restituir los predios de las víctimas del conflicto armado, pero aún más a aquellas víctimas que se encuentran expuestas a mayor riesgo y por tanto son más vulnerables; esto es, personas que aun siendo víctimas deben ser tratadas con más especialidad, es decir, niños, niñas, adolescentes,

34 Fallo en el que también se reconocerán los derechos a los que haya lugar sobre el predio objeto de la solicitud, en igualdad de condiciones para las parejas, cónyuges y compañeros permanentes de la víctima para la fecha del despojo y desplazamiento.

35 Relacionados en el artículo 73 de la Ley 1448/2011, de 10 de junio y desarrollados en general a lo largo de esta. 
personas de avanzada edad, mujeres y personas en situación de discapacidad, entre otros, con lo cual se dará lugar al principio de enfoque diferenciador dentro del grupo de víctimas, reconociéndolos como un subgrupo de especialísima protección, ya que cuentan con una serie de medidas diferenciales que responden a las particularidades y al grado de vulnerabilidad de las víctimas y que den acompañamiento preferente por parte del Estado y, por supuesto, este principio está en estrecha relación con el principio de prevalencia constitucional, el cual hace referencia a que las autoridades judiciales encargadas del procedimiento, ya mencionado a lo largo de este artículo, deben garantizar la prevalencia de los derechos de las víctimas del abandono y despojo forzado de sus tierras (Quintero y Molina, 2013).

$\mathrm{Y}$, finalmente, es preciso referirnos a otra particularidad, la cual va encaminada a la suspensión de procesos judiciales, notariales y administrativos que versen sobre el bien objeto de la solicitud, que se encuentren cursando antes de la presentación de esta, pues el juez tiene la facultad de ordenar tal suspensión dentro del auto que admita la demanda (Ley 1448/2011, de 10 de junio, art. 86, literal c) y así también podrá el juez de restitución de tierras ordenar la acumulación de procesos, administrativos, notariales o judiciales, que versen sobre el predio. Se deberán enviar a este juez todos los expedientes correspondientes que se estén adelantando sobre el predio solicitado, para que sea él quien determine y sintetice todas las actuaciones en un solo proceso, “otorgando con esto seguridad jurídica al fallo de restitución y evitando entonces que decisiones de otros despachos judiciales o de otras entidades administrativas o notariales, pongan en vilo lo decidido por el juez dentro del proceso de restitución” (Ponce, 2016), de tal manera que no se afecte el derecho fundamental protegido con esta acción.

\section{Conclusiones}

En primera medida, se puede referir, entonces, que esta acción mantiene un carácter especial toda vez que sostiene un procedimiento que consta de dos etapas: una administrativa y una judicial, las cuales son únicas de esta acción, y aun cuando la funcionalidad y finalidad de sus autoridades es de naturaleza civil, se pudo evidenciar que su fundamento principal está sostenido y arraigado a los mandamientos constitucionales, y así darles un reconocimiento y alcance de derecho fundamental a la restitución de tierras, al derecho a la propiedad de la tierra, así como al derecho a 
la reparación integral y al restablecimiento general de los derechos de las víctimas del conflicto armado interno.

En esa medida, no se puede catalogar tal acción en una especialidad del derecho, pues su fundamento jurídico y su finalidad están compuestas por diversas características que permiten evidenciar su esencia constitucional, civil, agraria, y, por supuesto, guarda una estrecha relación con los derechos humanos. Ciertamente, no hay duda de que todo ello va encaminado a proteger a las víctimas a través de la reparación integral, la seguridad jurídica de la restitución y la titularidad de los predios objeto de restitución, así como la protección a los derechos fundamentales que se desprenden de la tierra.

Cabe mencionar que de las 112939 solicitudes presentadas al 24 de mayo de 2018 solo se han podido culminar en etapa administrativa 60390 , de las cuales solo 7468 han sido resueltas por sentencia judicial (Unidad de Restitución de Tierras, 2018). Con esto, se puede denotar que, aunque el Gobierno Nacional ha puesto todo su interés en enfrentar legal, económica y humanamente las consecuencias del referido conflicto, sus intentos no han arrojado los resultados esperados, pero aun así se sigue trabajando por alcanzar lo antes posible una reparación integral a las víctimas, que gracias al fin de los tiempos de guerra se podrá empezar a conseguir el propósito tan anhelado de reparar a las víctimas y llevar a término la reconciliación del país.

\section{Referencias}

Álvarez Silva, A. (2016). Instrumentos jurídicos para la protección y restitución de tierras despojadas o abandonadas forzosamente. Via Inveniendi et Iudicandi, 11(2), 127-157. https://doi.org/10.15332/s1909-0528.2016.0002.06

Auto 008/2009, de 26 de enero, desplazamiento forzado.

Barragán Ronderos, D. (2016). La construcción de la mentalidad democrática como necesidad en el posconflicto. Via Inveniendi et Iudicandi, 11(1), 37-57. https://doi. org/10.15332/s1909-0528.2016.0001.06

Conpes 3715/2012, de 30 de mayo, lineamientos, plan de ejecución de metas, presupuesto y mecanismo de seguimiento para el Plan Nacional de Atención y Reparación Integral a las Víctimas. 
Coronado Delgado, S. A. (2010). Marcos legales para el acceso a la tierra en América Latina: una mirada comparativa en ocho países de la región. Bogotá, Colombia: Instituto Latinoamericano para una Sociedad y un Derecho Alternativos.

Daza, A. (2013). Legalidad y prescripción frente a la investigación de crímenes de lesa humanidad en Colombia. Revista IUSTA, 38, 205-223. DOI: https://doi.org/10.15332/ s1900-0448.2013.0038.08

Decreto 4829/2011, de 20 de diciembre, por el cual se reglamenta el Capítulo III del Título IV de la Ley 1448 de 2011 en relación con la restitución de tierras.

Díaz Gómez, C., Sánchez, N. C. y Uprimny Yepes, R. (2009). Reparar en Colombia: los dilemas en contextos de conflicto, pobreza y exclusión. Bogotá, Colombia: Centro Internacional para la Justicia Transicional. Recuperado de https://www.ictj.org/sites/default/ files/ICTJ-Colombia-Dilemas-Contextos-Conflicto-2009-Spanish.pdf

Fuentes, A. P. (2011). Serie marcos legales de acceso a la tierra: estudio Colombia. Coalición Internacional para el Acceso a la Tierra. Recuperado http://www.iepala.es/IMG/pdf/ ILC_Marcos_Legales_Tierra_Colombia.pdf

Gamboa Rubiano, S. R. (2016). A propósito de una verdad contrahegemónica: aprendizajes desde la decisión de la Corte Penal Internacional sobre el ataque contra la flotilla de la libertad. Via Inveniendi et Iudicandi, 11(1), 11-35. https://doi.org/10.15332/ s1909-0528.2016.0001.02

Guzmán Rincón, A. M. y Barón Rocha, N. R. (2018). Dimensión constitucional y mecanismos de la acción de restitución de tierras en Colombia. Revista de Derecho, 49, 142-169.

Ley 74/1926, de 30 de noviembre, sobre fomento a la agricultura y a la inmigración y se dictan otras disposiciones.

Ley 200/1936, de 16 de diciembre, sobre régimen de tierras.

Ley 975/2005, de 25 de julio, por la cual se dictan disposiciones para la reincorporación de miembros de grupos armados organizados al margen de la ley, que contribuyan de manera efectiva a la consecución de la paz nacional y se dictan otras disposiciones para acuerdos humanitarios. 
Ley 1437/2011, de 8 de enero, por la cual se expide el Código de Procedimiento Administrativo y de lo Contencioso Administrativo.

Ley 1448/2011, de 10 de junio, por la cual se dictan medidas de atención, asistencia y reparación integral a las víctimas del conflicto armado interno y se dictan otras disposiciones.

Martínez Sanabria, C. M. y Pérez Forero, A. C. (2012). La restitución de tierras en Colombia: expectativas y retos. Prolegómenos, 15(29), 111-127.

Ministerio de Agricultura y Desarrollo Rural (2012). ABC para los jueces en materia de restitución de tierras. Bogotá, Colombia: Autor. Recuperado de https://www.restituciondetierras. gov.co/documents/10184/227457/ABC.pdf/96b6eb53-16c4-42bc-8a0f-8be383c05c58

Moreno, T., Medina, J. L., Fuentes, A. P. y Lopera, A. (2016). Restitución de tierras en Colombia: análisis y estudios de caso. Bogotá, Colombia: Centro de Investigación y Educación Popular.

Moya, A. y Marulanda, M. (2012). Reparación transformadora, retorno y restitución de tierras: apuntes sobre artículo 101 de la Ley 1448 de 2011. Revista de Derecho Público, $31,143-165$.

Observatorio de Restitución y Regulación de Derechos de Propiedad Agraria (2013). Ley 1448 de 2011 sobre Restitución de tierras. Recuperado de https://www.javerianacali.edu. $\mathrm{co} /$ sites/ujc/files/node/field-documents/field_document_file/restituciondetierras.pdf

Pérez Bohórquez, A. C. (2013). El agotamiento previo de la acción de inconstitucionalidad para acceder al Sistema Interamericano de Protección de los Derechos Humanos. Verba luris, 30, 61-82.

Ponce Bravo, M. (2016). El juez de restitución de tierras: alcances y limites (Tesis de grado, Universidad del Rosario, Bogotá, Colombia). Recuperado de http://repository.urosario. edu.co/bitstream/handle/10336/13288/TESIS\%20DEFINITIVA.pdf?sequence=1

Quintero Cordero, S. P. y Molina Orjuela, D. E. (2013). La ilegalidad: una herramienta de análisis para la naturaleza del conflicto en Colombia. Via Inveniendi et Iudicandi, 8(1). DOI: https://doi.org/10.15332/s1909-0528.2013.0001.06 
Sänger, R. (2015). La garantía de la propiedad y el principio de proporcionalidad como límites de la carga tributaria en Alemania. IUSTA, 1(42), 73-99. https://doi.org/10.15332/ s1900-0448.2015.0042.04

Sentencia C-225/1995, de 18 de mayo, derecho internacional humanitario.

Sentencia C-774/2001, de 25 de julio, inhibición de la Corte Constitucional.

Sentencia T-025/2004, de 22 de enero, agencia oficiosa en tutela.

Sentencia C-370/2006, de 18 de mayo, ley de justicia y paz.

Sentencia T-821/2007, de 5 de octubre, derechos fundamentales de los desplazados.

Sentencia T-085/2009, de 16 de febrero, acción de tutela para obtener la reparación de perjuicios sufridos por los desplazados.

Sentencia T-159/2011, de 10 de marzo, acción de tutela para la protección de los derechos fundamentales de la población desplazada.

Sentencia T-580/2011, de 27 de julio, derecho a la propiedad privada.

Sentencia C-253A/2012, de 29 de marzo, cosa juzgada constitucional en ley de víctimas del conflicto armado.

Sentencia C-644/2012, de 23 de agosto, autorizaciones en Plan Nacional de Desarrollo a persona natural o jurídica para adquisición, aporte, uso o aprovechamiento de tierras baldías adjudicadas inicialmente como baldíos o adquiridas por subsidio integral.

Sentencia C-820/2012, de 18 de octubre, contratos para el uso de predio restituido en ley de reparación integral a víctimas del conflicto armado interno.

Sentencia C-715/2012, de 13 de septiembre, medidas de atención, asistencia y reparación integral a las víctimas del conflicto armado interno. 
Sentencia C-099/2013, de 27 de febrero, medidas de atención, asistencia y reparación integral a las víctimas del conflicto armado interno.

Sentencia T-679/2015, de 3 de noviembre, acción de tutela y requisito de subsidiariedad.

Sentencia C-330/2016, de 23 de junio, norma sobre medidas de atención, asistencia y reparación integral a víctimas del conflicto armado interno.

Unidad de Restitución de Tierras (2018). Infografía de restitución de tierras 2018, mayo 24 y mayo 25. Recuperado de https://www.restituciondetierras.gov.co/documents/10184/953221/infografia-de-Restitucion-de-Tierras-2018-MAYO-24-Y-MAYO-25.jpg/efd4bc08-ad28-433c-a8f8-051461a346bf?version=1.0\&t=1527867959429 